\title{
PEMBINAAN DAN PENGELOLAAN FAKTOR RISIKO MELALUI PENYULUHAN KESEHATAN CALON JEMAAH HAJI KABUPATEN JEMBER
}

\section{DEVELOPMENT AND MANAGEMENT OF RISK FACTORS THROUGH HEALTH COUNSELING FOR PROSPECTIVE HAJJ PILGRIMS, JEMBER DISTRICT}

\author{
Ika Rahmawati Sutejo ${ }^{* 1}$, Nur Hasyimiyyah ${ }^{* 1}$, Wiwien Sugih Utami* ${ }^{* 1,2}$, Baskoro Adi Prayitno*3 \\ ${ }^{*}$ Fakultas Kedokteran Universitas Jember, Jalan Kalimantan 37 Jember 68121 \\ ikarahmawati.fk@unej.ac.id \\ ${ }^{* 2}$ Prodi S3 Fakultas Kedokteran Universitas Gajah Mada, Jalan Farmako Sekip Utara Yogyakarta 55281 \\ wiwien.dr@unej.ac.id \\ *3 Prodi Pendidikan Biologi Fakultas Keguruan dan Ilmu Pendidikan Universitas Sebelas Maret, Jalan Ir. \\ Sutami 36 A Kentingan Surakarta \\ baskoro_apefkip.uns.ac.id
}

\begin{abstract}
Abstrak
Jumlah jemaah haji Indonesia mengalami peningkatan beberapa tahun terakhir, meski disertai pertambahan jumlah tenaga kesehatan, namun tidak sebanding dengan pelayanan kesehatan yang mereka butuhkan. Oleh karena itu, kegiatan pembinaan, pelayanan, dan perlindungan kesehatan jemaah haji tidak hanya dilaksanakan saat mereka di tanah suci, namun harus dimulai sejak awal saat jemaah haji masih di tanah air. Jumlah calon jemaah haji kabupaten Jember tahun 2018 sebanyak 1.981 orang. Separuh dari jumlah jemaah haji kabupaten Jember adalah lansia yang berusia lebih dari 60 tahun dengan kategori berisiko tinggi. Salah satu Kelompok Bimbingan Haji (KBIH) yang memiliki calon jemaah haji terbanyak di Jember adalah KBIH Al Ghazalie dengan jumlah jemaah 303 orang. Kegiatan pengabdian ini dilakukan melalui penyuluhan kesehatan dan pengumpulan data karakteristik jemaah. Target kegiatan pengabdian ini adalah calon jemaah haji KBIH Al Ghazaalie Jember. Luaran kegiatan ini selain meningkatkan pengetahuan dan kemandirian calon jemaah haji di bidang kesehatan, juga bertujuan mengungkap data karakteristik jemaah yang meliputi distribusi jenis kelamin, kelompok usia, dan jenis penyakit yang banyak diderita. Data ini menggambarkan kondisi riil kesehatan jemaah di lapangan, sehingga diharapkan menjadi fokus perhatian dalam pencegahan dan penanganan penyakit oleh tenaga kesehatan haji Indonesia. Penyuluhan kesehatan berisi materi mengenai penyakit-penyakit yang sering menyerang jemaah haji, status risiko kesehatan, penanganan pertama pada gangguan kesehatan jemaah haji, dan obat-obatan darurat yang disiapkan masing-masing jemaah haji. Karakteristik jemaah haji KBIH Al-Ghazaalie didominasi jemaah laki-laki, berusia 51-60 tahun, dengan penyakit terbanyak yaitu penyakit kardiovaskuler (hipertensi), diabetes melitus dan penyakit respirasi.
\end{abstract}

Kata Kunci - Jemaah haji, risiko tinggi, penyuluhan kesehatan, lansia, kardiovaskuler

Abstract

The number of Indonesian pilgrims has increased in recent years, although accompanied by an increase in the number of health workers, but it is not comparable to the health services they need. Therefore, the activities of guidance, service and health protection for the pilgrims are not only carried out when they are in the holy land, but must start from the beginning when the pilgrims are still in the country. The number of candidates for the Hajj pilgrimage in Jember Regency in 2018 was 1,981 people. Half of the number of pilgrims in Jember district are elderly people who are over 60 years old with the high risk category. One of the Hajj Guidance Groups (KBIH) that has the most prospective pilgrims in Jember is KBIH Al Ghazalie with a total of 303 people. This service activity is carried out through health education and collecting data on the characteristics of the congregation. The target of this service activity is the prospective Haj pilgrimage of KBIH Al Ghazaalie Jember. The outcome of this activity, apart from increasing the knowledge and independence of prospective pilgrims in the health sector, also aims to reveal the data on the characteristics of the congregation which include the distribution of gender, age group, and types of diseases that many suffer from. This data describes the real condition of the congregation's health in the field, so it is expected to be the focus of attention in the prevention and management of disease by Indonesian haj health workers. Health counseling contains material regarding diseases that often attack pilgrims, health risk status, first handling of pilgrims' health problems, and emergency medicines prepared by each pilgrim. The characteristics of the Hajj pilgrims at KBIH Al-Ghazaalie are dominated by male congregations, aged 51-60 years, with the most common diseases, namely cardiovascular disease (hypertension), diabetes mellitus and respiratory disease.

Keywords - Hajj pilgrims, high risk, health education, elderly, cardiovascular 


\section{PENDAHULUAN}

Pemerintah Arab Saudi memberikan kuota sebanyak 168.000 calon jemaah haji dari Indonesia pada tahun 2013. Pada tahun 2017 kuota jemaah haji Indonesia bertambah menjadi 221.000 jemaah dengan jumlah kloter sebanyak 507 kloter (Anggraini \& Paolo, 2018). Dari jumlah ini, 63\% jemaah masuk kelompok berisiko tinggi, sebagian besar karena usia lanjut (Kemenkes RI., 2017). Risiko wafat pada usia lanjut lebih tinggi. Jumlah jemaah usia lanjut atau lebih dari 60 tahun berkisar 20-25\% dari keseluruhan jemaah, tetapi sekitar 70\% jemaah wafat terjadi pada kelompok usia ini (Budiman, 2013). Selain usia lanjut, penyakit yang diderita jemaah haji sejak dari tanah air juga menjadi penyebab gangguan kesehatan dan kematian jemaah saat beribadah. Hipertensi merupakan penyakit terbanyak (25-37\%) yang diderita jemaah haji. Penyakit kardiovaskuler dan paru merupakan 2 penyebab kematian terbanyak pada jemaah haji (Kemenkes RI., 2015)

Sebagai bentuk perlindungan kesehatan jemaah, telah dilakukan penambahan petugas kesehatan seiring dengan penambahan jumlah jemaah tersebut. Tenaga kesehatan haji terdiri dari tenaga kesehatan kloter (kelompok terbang) atau Tim Kesehatan Haji Indonesia (TKHI) pada tahun 2017 sebanyak 1.521 orang, terdiri 507 dokter dan 1.014 perawat. TKHI kloter terdiri 1 dokter dan 2 perawat ini selalu menyertai jemaah haji dalam kelompok penerbangan, sehingga setiap keluhan jemaah haji bisa langsung mendapat penanganan. Sedangkan tenaga kesehatan non kloter yang sering disebut Panitia Penyelenggara Ibadah Haji (PPIH) bidang kesehatan yang bertugas di Arab Saudi sebanyak 268 orang (Kemkes RI., 2017). Jumlah ini masih diakui tidak sebanding dengan jumlah jemaah haji yang memerlukan pelayanan kesehatan. Sehingga upaya penyelenggaraan kesehatan haji di Indonesia yang merupakan serangkaian kegiatan pembinaan, pelayanan dan perlindungan kesehatan jemaah dilaksanakan jauh sejak awal sebelum keberangkatan ke tanah suci (Kemenkes RI., 2009).

Upaya pembinaan dilaksanakan sejak dini di tanah air, bertujuan untuk meningkatkan pengetahuan, sikap dan perilaku hidup bersih dan sehat jemaah, sehingga mampu sehat secara mandiri. Kegiatannya melalui pembelajaran dari, oleh, dan bersama jemaah haji, sesuai sosial budaya setempat. Ruang lingkup kegiatan meliputi peningkatan pemahaman perjalanan ibadah haji sebagai kondisi matra yang berpengaruh terhadap kesehatan, manajemen berhaji sehat dan mandiri, persiapan kesehatan (fisik dan psikis), logistik dan keperluan kesehatan untuk melaksanakan perjalanan ibadah haji. Kegiatan bimbingan dan penyuluhan kesehatan jemaah haji ini dilakukan secara perorangan, berkelompok, maupun kemitraan, yang bekerjasama dengan komunitas di masyarakat, misalnya kelompok pengajian (majlis ta'lim), KBIH, Asosiasi Muslim Penyelenggara Haji Umroh Republik Indonesia (AMPHURI) dan sebagainya (Kemenkes RI, 2009).

Jemaah haji kabupaten Jember pada tahun 2018 mencapai 1.981 orang (Kemenag Jember, 2018). Separuh dari jumlah jemaah Jember tersebut berusia lebih dari 60 tahun, yang termasuk dalam risiko kesehatan tinggi. Jemaah haji risiko tinggi adalah jemaah haji dengan kondisi kesehatan yang berisiko sakit dan atau meninggal selama perjalanan ibadah haji. Jemaah yang masuk dalam kategori risti meliputi: 1) Jemaah haji lanjut usia, 2) Jemaah haji penderita penyakit menular tertentu yang tidak boleh keluar dari Indonesia berdasarkan peraturan kesehatan yang berlaku, 3) Wanita hamil, 4) Jemaah haji dengan ketidakmampuan tertentu terkait penyakit kronis dan atau penyakit tertentu lainnya (Kemenkes RI., 2010). Kelompok risti usia lanjut ini menjadi proporsi terbesar kematian jemaah dan jamaaah yang membutuhkan perawatan pada tahun 2014-2016 (Kemenkes RI., 2017)

Jumlah jemaah haji yang terdaftar pada Kelompok Bimbingan Ibadah Haji (KBIH) Al Ghazaalie merupakan salah satu yang terbanyak, yaitu 303 orang. Jemaah haji tersebut berasal dari seluruh kecamatan yang ada di wilayah kabupaten Jember. Hasil wawancara langsung terhadap perwakilan jemaah haji menunjukkan jemaah telah melakukan pemeriksaan kesehatan di puskesmas wilayah masing-masing dan melaksanakan imunisasi meningitis, akan tetapi jemaah masih merasa pengetahuan mengenai status kesehatan pribadi, penyakit-penyakit yang sering menyerang jemaah haji dan pencegahannya penggolongan kelompok risiko kesehatan, serta daftar obat pribadi yang harus disiapkan masih kurang. Beberapa dari jemaah juga menyadari bahwa mereka menyandang penyakit degeneratif seperti hipertensi, diabetes, obesitas, dll., sehingga jemaah membutuhkan saran berkaitan dengan penyakit masing-masing agar pelaksanaan ibadah haji berjalan lancar. Latar belakang tersebut mendorong kami melaksanakan suatu kegiatan pengabdian masyarakat berupa penyuluhan kesehatan serta pengumpulan data karakteristik jemaah, yang dilakukan bersamaan dengan manasik calon jemaah haji KBIH Al-Ghazaalie kabupaten Jember. Kegiatan pembinaan calon jemaah haji terutama difokuskan pada jemaah dengan karakeristik tertentu yang memiliki risiko tinggi.

\section{TARGET DAN LUARAN}

Target kegiatan pengabdian ini sebanyak tiga ratus tiga orang calon jemaah haji dari $\mathrm{KBIH} \mathrm{Al}$ Ghazaalie Jember. Luaran kegiatan ini selain menghasilkan peningkatkan pengetahuan dan 
kemandirian jemaah di bidang kesehatan, juga terdapat data distribusi jenis kelamin, kelompok usia dan jenis penyakit yang banyak diderita jemaah. Data ini diharapkan menjadi gambaran kondisi kesehatan jemaah, yang akan diberikan perhatian lebih dalam pencegahan dan penanganan penyakit oleh tenaga kesehatan haji Indonesia METODE PELAKSANAAN

Kerangka penyelesaian masalah yang diterapkan adalah pendekatan pelayanan kesehatan, dengan upaya kesehatan pencegahan (promotif) dan screening serta penentuan risti (risiko tinggi) calon jemaah haji. Upaya kesehatan pencegahan dilakukan melalui penyuluhan penyakit-penyakit yang sering menyerang jemaah haji, status risiko jemaah, penanganan pertama pada gangguan kesehatan jemaah haji, dan obat-obatan utama yang disiapkan masing-masing individu jemaah haji. Kegiatan dilaksanakan bersama manasik calon jemaah haji yang diselenggarakan KBIH AL Ghazaaliee kabupaten Jember. Manasik dilaksanakan setiap hari minggu selama 12 minggu sejak Januari-April 2018. Tim kesehatan diberikan kesempatan 2 kali pertemuan, pertama untuk pengumpulan data karakteristik dan jenis penyakit jemaah dan kedua untuk pelaksanaan penyuluhan. Screening dilakukan melalui anamnesis dan pemeriksaan fisik calon jemaah, dari data tersebut jemaah kemudian dikategorikan dalam risiko tinggi (risti) atau tidak. Jemaah tergolong dalam risti/mempunyai masalah kesehatan diberikan waktu konseling khusus dalam bentuk diskusi tanya jawab mengenai masalah kesehatan yang disandangnya.

Kegiatan penyuluhan Kesehatan dilaksanakan pada hari Minggu, 29 April 2018 di Aula KBIH AlGhazaalie jl. Yos Sudarso 115 Kranjingan Sumbersari Kabupaten Jember. Pengurus KBIH Al Ghazaalie yang hadir sejumlah 10 orang bertugas di bagian perlengkapan dan meja registrasi. Kegiatan dimulai dengan registrasi peserta pada pukul 08.00 WIB. Pukul 09.00-11.00 penyuluhan diberikan dilanjutkan dengan diskusi tanya jawab. Pemberian materi penyuluhan dilakukan menggunakan media visual berupa powerpoint.

\section{HASIL DAN PEMBAHASAN}

Ibadah haji merupakan ibadah fisik, sehingga jemaah haji dituntut mampu secara fisik, selain rohani, agar dapat melaksanakan rangkaian ibadah haji dengan baik dan lancar. Salah satu penyelenggaraan kesehatan haji yang sangat penting dan strategis adalah serangkaian upaya kegiatan melalui program pemeriksaan dan pembinaan kesehatan haji, agar terpenuhi kondisi istitha'a kesehatan. Istitha'ah kesehatan merupakan kemampuan kesehatan jemaah haji untuk melakukan serangkaian aktivitas rukun dan wajib haji. Istitha,ah sebelum keberangkatan berarti jemaah dapat menjaga dan mempertahankan kesehatan fisiknya hingga tiba saatnya untuk ditentukan kelaikan terbang (Kurniasih, 2018).

Jumlah calon jama'ah haji kabupaten Jember pada tahun 2017 sebanyak 1.981 orang. Jumlah ini terbesar keempat di Jawa Timur, setelah Kota Surabaya, Kota Malang, dan Kabupaten Sidoarjo (Kemenag Jatim, 2018). Jumlah jemaah haji dari KBIH Al Ghazaalie merupakan salah satu jemaah KBIH yang terbanyak, yaitu sebanyak 303 jemaah. Jemaah haji tersebut berasal dari seluruh kecamatan yang ada di wilayah jember, diantaranya adalah kecamatan Sumbersari, Kaliwates, Patrang, Arjasa, Rambipuji, Ajung, Jemnggawah, Mumbulsari, Mayang, Pakusari, Kalisat, Ledokombo, Silo, Panti, Umbulsari, Puger, Kencong, Bangsalsari, Balung, Ambulu, Wuluhan, dan Sukorambi.

Distribusi calon jemaah haji KBIH Al-Ghazaalie menurut jenis kelamin menunjukkan sebanyak 157 jemaah laki-laki dan sisanya 146 perempuan (Gambar 1). Proporsi jemaah menurut jenis kelamin di KBIH Al Ghazaliie ini tidak sesuai dengan data karakteristik jemaah haji nasional, yang menunjukkan jumlah jemaah perempuan lebih banyak daripada laki-laki (Kemenkes RI., 2017; Kemenkes RI., 2015). Kelompok usia jemaah terbanyak adalah 50-59 tahun, yaitu sebanyak 124 orang, sedangkan jemaah berusia $\geq 60$ tahun sebanyak 92 orang. Dari jumlah ini, sebanyak 16 orang berusia $\geq 70$ tahun (Gambar 2). Semakin tua usia jemaah, semakin kompleks kondisi kesehatannya, akibat menurunnya fungsi tubuh, akumulasi penyakit, keterbatasan fisik dan kemandirian. Jemaah berusia kurang dari 30 tahun hanya berjumlah 4 orang. Persebaran data jumlah jemaah berdasar kelompok usia ini sesuai dengan data jemaah nasional, yang menunjukkan proporsi terbesar pada kelompok umur 51-60 tahun dan paling sedikit pada kelompok umur $<40$ tahun (Kemenkes RI., 2017; Kemenkes RI., 2015). Banyaknya jemaah usia lanjut salah satunya dikarenakan waktu tunggu berhaji yang cukup lama. Jemaah haji kabupaten Jember tahun 2018 ini menunggu kurang lebih 8 tahun dari waktu mendaftar sampai dengan waktu keberangkatan.

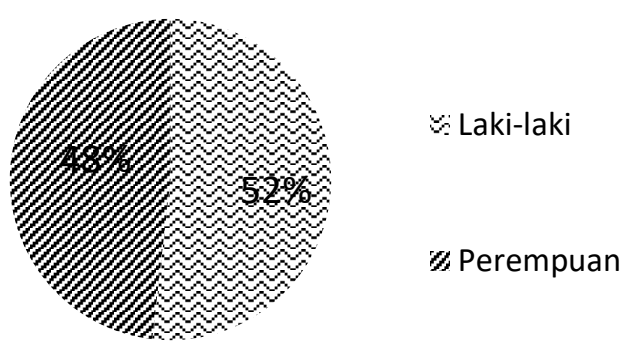




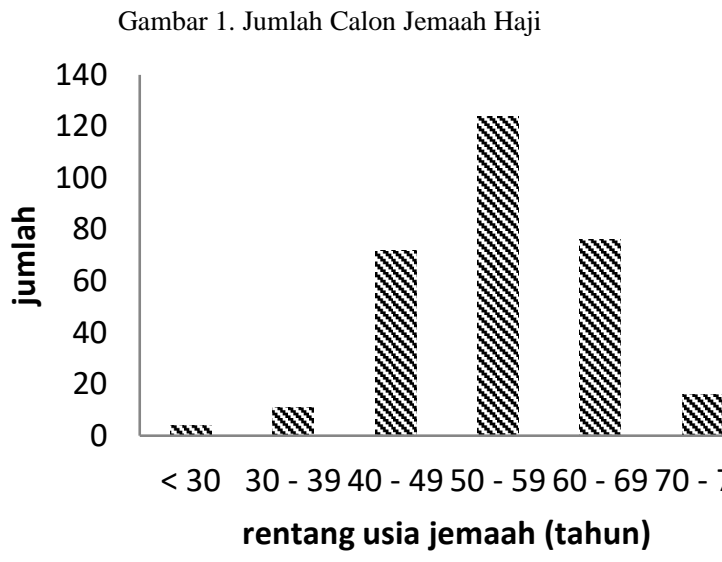

Gambar 2. Distribusi Usia Calon Jemaah Haji

Kelompok usia lebih dari 60 tahun (lansia) masuk dalam risti meskipun tidak menderita penyakit. Terdapat tiga kriteria jemaah haji risti. Kelompok pertama, diberi gelang hijau. Kelompok kedua, gelang kuning. Sedangkan kelompok ketiga, gelang merah. kelompok pertama merupakan jemaah haji risti yang berusia lebih dari 60 tahun namun dikategorikan sehat. Kelompok kedua, yakni jemaah haji risti yang berusia kurang dari 60 tahun namun memiliki penyakit yang sudah terdeteksi sejak di tanah air. Sedangkan kelompok ketiga, berusia lebih dari 60 tahun dan juga memiliki penyakit (Kementrian Kesehatan RI, 2015). Pengawasan dan penanganan kesehatan pada tiap kelompok ini berbeda. Akan tetapi di tahun 2018, ketiga warna gelang tersebut diubah menjadi gelang satu warna saja yaitu gelang oranye. Alasan khusus Kemenkes mengubah kebijakan untuk optimalisasi pengendalian faktor risiko kesehatan jemaah haji dan juga untuk meminimalisir masalah psikis yang dialami jemaah, sehingga jemaah haji yang tergolong dalam kategori kelompok risiko tinggi yang akan menerima gelang oranye (Nuraeni, 2018).

Data penyelenggaraan ibadah haji nasional menunjukkan pola mortalitas dan morbiditas pada kelompok tertentu. Jenis kelamin laki-laki dan usia lebih dari 60 tahun memiliki morbiditas dan mortalitas yang tinggi dibanding kelompok lainnya (Kemenkes RI., 2017). Tingkat pendidikan jemaah haji Indonesia didominasi lulusan SD, sedangkan lulusan S1, S2, dan S3 lebih sedikit dibanding lulusan SD, SMP dan SMA (Kemenkes RI., 2015). Selain masalah kesehatan yang disebabkan karena jemaah haji lanjut usia, jemaah haji non-risti sebagian besar masih memiliki pengetahuan, sikap, dan perilaku kesehatan yang belum mengarah pada perilaku hidup sehat dan mandiri disebabkan karena masih besarnya proporsi jemaah dengan tingkat pendidikan rendah tersebut (Wahjudi \& Putriana, 2014).

Tim pelaksana melakukan upaya mengatasi kurangnya pengetahuan tentang penyakit yang banyak diderita calon jemaah haji dengan melakukan penyuluhan kesehatan (upaya kesehatan promotif). Kegiatan penyuluhan berjalan dengan lancar (Gambar 3). Calon jemaah haji yang tergabung pada KBIH Al Ghazaalie Jember antusias mengikuti kegiatan penyuluhan kesehatan. Hal ini nampak dari sesi diskusi yang dipenuhi pertanyaan dari peserta. Pertanyaan kesehatan berhubungan dengan ibadah haji berlanjut menjadi konsultasi perorangan di luar waktu penyuluhan. Beberapa pertanyaan yang banyak disampaikan jemaah diantaranya mengenai penyakit degeneratif (hipertensi, diabetes melitus, stroke, dislipidemia, dll.), penyakit infeksi (tuberkulosis, ISPA), asma, gangguan pencernaan, serta cara pengaturan siklus haid yang banyak ditanyakan jemaah perempuan usia subur. Pertanyaan yang disampaikan sesuai dengan data penyakit yang banyak diderita calon jemaah haji KBIH Al-Ghazaalie, yaitu penyakit jantung dan pembuluh darah (hipertensi, kardiomegali, HHD), diabetes melitus serta gastritis (Tabel 1).

Data jumlah penyakit terbanyak tersebut sesuai kondisi jemaah haji nasional. Penyakit degeneratif, metabolik dan kronis masih mendominasi sebagai penyakit yang diderita oleh jemaah haji terutama usia lanjut. Setiap tahunnya, jemaah haji Indonesia yang wafat di Arab Saudi sebagian besar disebabkan oleh penyakit jantung, pernapasan, ginjal, metabolik, dan hipertensi. Laporan Siskohatkes tahun 2016 menunjukan penyebab wafat jemaah haji 53\% karena penyakit kardiovaskular, $27 \%$ penyakit respirasi, serta 78,8\% berusia lebih dari 60 tahun (Siskohatkes, 2016). Sehingga petugas kesehatan haji harus dibekali penguasaan yang lebih mendalam dan kewaspadaan terhadap kondisi penyebab mortalitas dan morbiditas terbanyak tersebut.

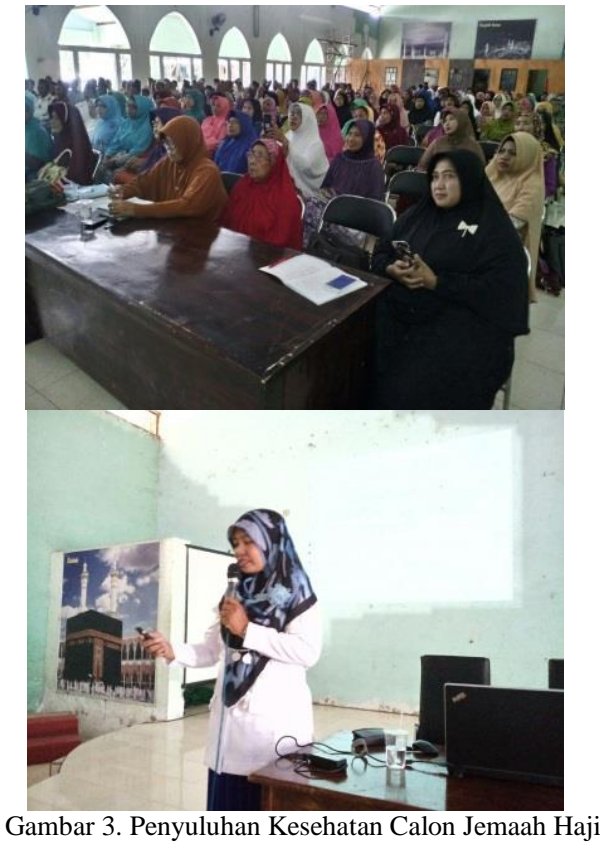


Pemberian penyuluhan kesehatan disampaikan dalam bahasa awam yang mudah dimengerti jemaah. Untuk memudahkan, Tim pelaksanaa menjelaskan kondisi risiko tinggi jemaah haji dibagi menjadi dua kategori,

yaitu risti sehat dan risti sakit. Risti Sehat adalah kondisi jemaah yang tidak mengidap penyakit apa pun namun keadaan fisiknya memudahkan penyakit tertentu menyerang.

Kondisi yang memudahkan seseorang terserang penyakit, misalnya usia lanjut (usia 60 tahun atau lebih), obesitas, kaheksia atau kekurangan berat badan mencolok, dan cacat fisik, baik bawaan atau cacat yang menimbulkan gangguan melaksanakan aktifitas sehari-hari. Jemaah haji dikategorikan ke dalam kelompok risti sakit, jika menderita penyakit kronis. Bagi orang yang mengidap Risti Sakit, saransaran yang diberikan adalah: 1. Memeriksakan kondisi kesehatan secara teratur. Meskipun kondisi tubuh tidak bisa dipulihkan karena penyakit, setidaknya penyakit tersebut bisa dikendalikan selama mengerjakan ibadah haji; 2. Penderita diabetes melitus harus mempertahankan kadar gula normal. Jika ada penyakit lain yang menyertai atau terjadi komplikasi, seperti adanya borok atau luka, maka jemaah perlu dirawat dan kondisinya distabilkan sebelum keberangkatan. Obat yang digunakan setiap jemaah diabetes melitus tidak sama, sehingga harus membawa obat sendiri; 3. Jemaah penderita hipertensi harus membiasakan diet rendah garam; 4. Jemaah pengidap penyakit paru-paru kronis harus berobat intensif agar penyakit tidak aktif. Jemaah pengidap asma, sesak napas, atau penyakit paru-paru obstruktif menahun disarankan menghindari asap rokok atau polusi udara. Menggunakan masker, menghindari kelelahan, beristirahat yang cukup, tidak minum minuman dingin, dan tidak memaksa diri untuk melakukan ibadah sunnah yang menguras tenaga dapat membantu meminimalisir kekambuhan penyakit; 5 . Jemaah haji pengidap penyakit jantung seperti penyakit jantung koroner, penyakit jantung hipertensi harus membatasi aktifitas fisik dan obatobat jantung harus diminum secara teratur sesuai dengan petunjuk dokter.

Tabel 1. Penyakit Terbanyak

\begin{tabular}{|l|c|l|c|}
\hline No. & ICD X & Diagnosis & Jumlah \\
\hline 1 & A15 & Respiratory tuberculosis & 2 \\
\hline 2 & C53 & Malignant neoplasm of cervix uteri & 1 \\
\hline 3 & D25 & Leiomyoma of uterus & 1 \\
\hline 4 & D50 & Iron deficiency anemia & 1 \\
\hline 5 & E10 & Insulin Dependen Diabetes Melitus & 2 \\
\hline 6 & E11 & $\begin{array}{l}\text { Non Insulin Dependen Diabetes } \\
\text { Melitus }\end{array}$ & 16 \\
\hline 7 & E66 & Obesity & 1 \\
\hline 8 & E78 & Hypercholesterolemia & 4 \\
\hline 9 & E79 & Hyperuricemia & 2 \\
\hline 10 & I10 & Primary hypertension & 30 \\
\hline 11 & I11 & Hypertensive heart disease & 8 \\
\hline
\end{tabular}

\begin{tabular}{|l|c|l|c|}
\hline 12 & I21 & Acute Myocardial Infarction & 2 \\
\hline 13 & I24 & Other ischemic heart disease & 1 \\
\hline 14 & I25 & Atherosclerotic heart disease & 2 \\
\hline 15 & I45 & Right bundle branch block & 1 \\
\hline 16 & I50 & Heart failure & 1 \\
\hline 17 & I51 & Cardiomegali & 4 \\
\hline 18 & I95 & Hypotension & 1 \\
\hline 19 & J18 & Pneumonia & 1 \\
\hline 20 & K29 & Gastritis \& duodenitis & 5 \\
\hline 21 & L20 & Atopic dermatitis & 1 \\
\hline 22 & L23 & Alergic contact dermatitis & 1 \\
\hline 23 & M79 & Neuralgia and neuritis & 3 \\
\hline
\end{tabular}

Tim pelaksana pengabdian menyampaikan kiat meningkatkan kondisi fisik dan mental untuk seluruh calon jemaah haji KBIH Al-Ghazaalie sehingga dapat menyesuaikan diri terhadap lingkungan yang berubah, mulai dari sebelum berangkat sampai dengan 2 minggu setelah kepulangan dari tanah suci, yaitu 1) Meninggalkan pola hidup tidak sehat seperti kebiasaan merokok, begadang, makan yang tidak sehat, dan menggantikannya dengan pola hidup sehat seperti banyak minum air putih, sayur dan buah, makan tepat waktu, serta menjaga berat badan supaya ideal 2) Menghindari stress, 3) Olahraga secara teratur, seperti latihan jalan kaki sejuh $3 \mathrm{~km}$ setiap hari menggunakan alas kaki, 4) Mengkonsultasikan dengan tenaga kesehatan, terutama jemaah risti tentang apa saja yang tidak boleh dilakukan dan yang boleh dilakukan, selalu membawa obat-obatan yang dibutuhkan sesuai penyakit yang diderita, serta kemungkinan pencetus timbulnya penyakit ketika berada di tanah suci, cara mencegah dan mengatasinya. Tim pelaksana pengabdian juga memberikan daftar obat-obatan darurat yang sebaiknya disiapkan untuk kebutuhan masing-masing jemaah (Tabel 2).

Tabel 2. Daftar Obat Pribadi Jemaah Haji

\begin{tabular}{|l|l|} 
No. & \multicolumn{1}{|c|}{ Nama obat } \\
\hline 1. & Obat flu \\
\hline 2. & Obat batuk/pengencer dahak \\
\hline 3. & Asam Mefenamat/antinyeri \\
\hline 4. & Antialergi/Mebhidrolin \\
\hline 5. & Antidiare/attapugite \\
\hline 6. & Obat lambung/cimetidin \\
\hline 7. & Antimabuk/ Dimenhidrinat \\
\hline 8. & Multivitamin \\
\hline 9. & Pelembab/vaselin \\
\hline 10. & Minyak kayu putih/obat gosok \\
\hline 11. & Obat pribadi (Diabetes/ Hipertensi/ Asma) \\
\hline 12. & Pengatur haid (wanita usia subur) \\
\hline
\end{tabular}

\section{KESIMPULAN}

Dari keseluruhan rangkaian kegiatan pengabdian ini dapat disimpulkan Tim pelaksana melakukan 
upaya mengatasi kurangnya pengetahuan tentang penyakit yang banyak diderita calon jemaah haji dengan melakukan penyuluhan kesehatan (upaya kesehatan promotif) dan calon jemaah haji yang tergabung pada KBIH Al Ghazaalie Jember antusias mengikuti kegiatan bakti sosial penyuluhan kesehatan.

Saran bagi calon jemaah haji, diharapkan dapat melanjutkan upaya meningkatkan derajat kesehatan dengan memperluas pengetahuan di bidang kesehatan. Bagi pelaksana pelayanan kesehatan haji, diharapkan terus meningkatkan upaya kesehatan promotif dan kuratif sesuai data yang diperoleh dari kegiatan ini.

\section{UCAPAN TERIMA KASIH}

Terima kasih kepada KBIH Al Ghazaalie dan Asosiasi Kesehatan Haji Indonesia kabupaten Jember sehingga kegiatan pengabdian ini dapat terlaksana.

\section{DAFTAR PUSTAKA}

[1] Anggraini, A. D. \& Paolo, B., 2018. Kuota Haji Indonesia. https://indonesiabaik.id/infografis/kuota-haji-indonesia2010-2018.

[2] Budiman, A. R., 2013. Respon Jemaah Haji Terhadap Pelayanan Kesehatan pada Dinas Kesehatan Daerah Kabupaten Bekasi Tahun 2013. Jakarta: UIN Syarif Hidayatullah. Skripsi.

[3] Kemenag Jatim, 2018. Kuota Jemaah Haji 2018 Capai 35.035 Orang, Jumlah Terbanyak Berasal dari Empat Daerah Ini. http://jatim.tribunnews.com/2018/03/25/kuotajemaah-haji-2018-capai-35035-orang-jumlah-terbanyakberasal-dari-empat-daerah-ini

[4] Kemenag Jember, 2018. Kuota Haji 2018 di Jember sebanyak 1.981 Jemaah.http://rri.co.id/post/berita/547415/info_haji_2018/k uota_haji2018_di_jember_sebanyak_1981_jemaah.html

[5] Kemenkes RI., 2009. Pedoman Penyelenggaraan Kesehatan Jemaah Haji (Keputusan Menkes RI No. 442/MENKES/SK/VI/2009).

[6] Kemenkes RI., 2015. Situasi Kesehatan Jemaah Haji Indonesia.Pusat Data dan Informasi Kementrian Kesehatan RI.

[7] Kemenkes RI., 2017. Analisis Haji Indonesia 2017. Jakarta: Kementrian Kesehatan RI.

[8] Kemkes RI., 2017. Kemenkes Siapkan 1.963 Tenaga Penyelenggara Kesehatan Haji 2017. http://www.depkes.go.id/article/view/17071400004/kemen kes-siapkan-1-963-tenaga-penyelenggara-kesehatan-haji2017.html

[9] Kurniasih, S., 2018. Isthita'ah Kesehatan Jemaah Haji dalam Perspektif Kementrian Kesehatan RI. Jakarta: UIN Syarif Hidayatullah. Skripsi.

[10] Nuraeni, N., 2018. Sinergitas Pemerintah dalam Persiapan Penyelenggaraan Kesehatan Haji. Istitha'ah: Buletin Pusat Kesehatan Haji Kementerian Kesehatan RI, vol 01 hal 14.

[11] Wahjudi, P. \& Putriana, M.F. 2014. Karakteristik dan Status Kesehatan Jemaah Haji Kabupaten Banyuwangi Tahun 2012. IKESMA Volume 10 Nomor 1 Maret 2014 